Research Paper

\title{
Early Adverse Events predict Survival Outcomes in HER2-positive Advanced Breast Cancer Patients treated with Lapatinib plus Capecitabine
}

\author{
Fang L.I. Ang ${ }^{\bowtie}$, Andrew Rowland, Natansh D. Modi, Ross A. McKinnon, Michael J. Sorich, Ashley M. \\ Hopkins \\ College of Medicine and Public Health, Flinders University, Bedford Park, Adelaide, Australia \\ $\square$ Corresponding author: Fang Ling Ivy Ang, Room 5D317, Flinders Medical Centre, Bedford Park, Adelaide, SA 5042, Australia. Tel: +61 882015647 ; Fax: +61 8 \\ 8201 5647; E-mail: ang0089@flinders.edu.au \\ (c) The author(s). This is an open access article distributed under the terms of the Creative Commons Attribution License (https://creativecommons.org/licenses/by/4.0/). \\ See http://ivyspring.com/terms for full terms and conditions.
}

Received: 2019.11.11; Accepted: 2020.02.05; Published: 2020.03.05

\begin{abstract}
Background: This study aimed to investigate the impact of early adverse events (AE) following the initiation of lapatinib plus capecitabine on the progression-free survival (PFS) and overall survival (OS) outcomes of human epidermal growth factor receptor 2 (HER2) positive advanced breast cancer (ABC) patients.

Methods: A secondary analysis of participants treated with lapatinib plus capecitabine, or ado-trastuzumab emtansine in the clinical trial EMILIA was conducted. Cox proportional hazard analysis was used to assess the impact of $A E$ occurring within the first 42 days of lapatinib plus capecitabine therapy on the PFS and OS outcomes of $A B C$ patients.

Results: The study included 488 HER2-positive $(A B C)$ patients initiated on lapatinib plus capecitabine. Rash (Hazard Ratio (HR) [95\% Confidence Interval $(\mathrm{Cl})$ ]: Grade $1=0.67$ [0.46-0.98], Grade 2+ $=0.71$ $[0.42-1.19] ; p=0.046)$ and hand-foot syndrome (HR [95\% Cl]: Grade $1=0.58$ [0.43-0.80], Grade 2+= 0.61 [0.43-0.86]; $p=<0.001$ ) occurring within the first 42 days of lapatinib plus capecitabine therapy were significantly associated with improved OS. Conversely, nausea and vomiting occurring within the first 42 days of lapatinib plus capecitabine therapy was significantly associated with worsened OS (HR [95\% Cl]: Grade $1=1.08$ [0.82-1.42], Grade 2+ = 1.52 [1.13-2.03]; $p=0.027)$.

Conclusions: Rash and hand-foot syndrome occurring early after the initiation of on lapatinib plus capecitabine were significantly associated with improved OS, while early nausea and vomiting was associated with worse OS. In HER2-positive ABC patients initiating lapatinib plus capecitabine, consideration should be given to more closely monitoring patients at risk of nausea and vomiting, while rash and hand foot syndrome are $A E$ associated with improved survival.
\end{abstract}

Key words: adverse events, breast neoplasms, capecitabine, hand-foot syndrome, lapatinib, survival analysis

\section{Introduction}

Lapatinib (a dual epidermal growth factor receptor (EGFR) and human epidermal growth factor receptor 2 (HER2) inhibitor) and capecitabine (an oral prodrug of 5-fluorouracil) play an important role in later-line treatments of HER2-positive ABC [1-3]. This includes patients who experience disease progression on trastuzumab, anthracyclines and taxanes [4], patients with brain metastases (due to lapatinib's ability to penetrate the blood-brain barrier) $[5,6]$, and patients at risk of cardiac events (lapatinib is less cardiotoxic as compared to trastuzumab) [7].

While lapatinib plus capecitabine is an important treatment for HER2-positive $A B C$, there is significant variability in survival between patients [8]. Correspondingly there has been research to identify markers predictive of survival outcomes from lapatinib plus capecitabine therapy, which ultimately may be used to develop strategies to improve treatment outcomes. 
Preliminary evidence indicates that early lapatinib plus capecitabine induced AE may be associated with improved survival outcomes. For example, lapatinib plus capecitabine induced rash, hand foot syndrome and diarrhoea have been associated with improved PFS in a small cohort of 76 HER2-positive ABC patients [9]. Early lapatinib-related rash (within 42 days) has been significantly associated with OS and a trend towards improved disease free survival in a cohort of 3973 HER2-positive early breast cancer patients receiving adjuvant therapy [10]. Hand foot syndrome has also been associated with longer time-to-treatment failure in patients treated with capecitabine (with or without trastuzumab/ irinotecan; $\mathrm{n}=98$ ) [11]. The aim of this study was to comprehensively assess the association between early $\mathrm{AE}$ induced by lapatinib plus capecitabine therapy on the survival outcomes of HER2-positive ABC patients.

\section{Methods}

\section{Study design and patients}

This study analysed individual-participant data collected within the randomized trial EMILIA (NCT00829166) [8, 12]. EMILIA included HER2positive advanced breast cancer patients who underwent prior treatment with trastuzumab and a taxane. Participants were randomly assigned in a 1:1 ratio to either lapatinib plus capecitabine (oral lapatinib $1250 \mathrm{mg}$ per day; oral capecitabine 1000 $\mathrm{mg} / \mathrm{m}^{2}$ twice per day on days 1 to 14 every 21 days), or to ado-trastuzumab emtansine $(3.6 \mathrm{mg} / \mathrm{kg}$ intravenously every 21 days) [8, 12]. Dose delays, reductions, and discontinuations owing to toxic effects are defined in the EMILIA study protocol [8, 12]. Briefly, for capecitabine, the first dose reduction was to $75 \%$ of the total daily dose, and the second to $50 \%$ of that dose $[8,12]$. For lapatinib, the first dose reduction was to $1000 \mathrm{mg}$ daily, and the second to 750 mg daily [8, 12]. Patients could continue to take lapatinib if capecitabine was discontinued and vice versa [8, 12]. If treatment with both drugs was delayed for more than 42 consecutive days, the drugs were discontinued $[8,12]$.

\section{Predictor and outcome data}

Outcomes evaluated were PFS and OS. PFS was defined from randomization to progression or death from any cause, independently assessed according to the modified Response Evaluation Criteria in Solid Tumours version 1.0 (mRECIST 1.0). OS was defined from randomization to death from any cause, or censored at the date last known to be alive $[8,12]$.

Grading of AE severity was defined according to the National Cancer Institute Common Terminology Criteria for Adverse Events version 3.0 (CTCAE) [8,
12]. AE were evaluated in EMILIA according to Standardized MedDRA Queries, and MedDRA preferred terms were used in this analysis $[8,12]$. AE that were relatively common early after the initiation of lapatinib plus capecitabine therapy were evaluated for association with OS/PFS in this study. Rash was a combined variable of MedDRA preferred terms rash, exfoliative rash, rash pruritic, rash macular, rash erythematous, rash pustular, rash maculo-papular, rash papular, rash vesicular, and rash generalized.

\section{Statistical analysis}

The primary analysis used a landmark Cox proportional hazard model to investigate the association between survival outcomes and maximum grade of $\mathrm{AE}$ at the landmark time. Only $\mathrm{AE}$ occurring by the landmark time (first 42 days of lapatinib plus capecitabine therapy) were included, and patients that progressed or died before the landmark time were excluded from the analysis. The landmark point was derived according to a balance of being as early as possible (as early markers of response are more useful, and there is a loss of individuals/power as the landmark time increases due to the event occurring before the landmark) and ensuring enough adverse events had occur before the landmark time (as only adverse events before the landmark count in the analysis technique). Associations were reported as HR with 95\% CI, and $p$ values (likelihood ratio test). Kaplan-Meier analysis was used assess the effects of AE predictors on OS and PFS.

Sensitivity analysis of identified associations was conducted, including a time-dependent Cox proportional hazard regression to model the association between $\mathrm{AE}$ and survival outcomes. Time-dependent Cox proportional hazards analyses adjusted for pre-treatment age, race (white and non-white), ECOG performance status, visceral disease status, months since diagnosis, progesterone receptor status, estrogen receptor status, and any prior anthracycline in any setting, were also conducted.

All statistical analyses were performed with $\mathrm{R}$ (version 3.4.3).

\section{Results}

Data from 488 HER2-positive ABC patients initiated on lapatinib plus capecitabine were available. Median follow-up [95\%CI] was 45.2 [43.049.6] months. The pre-treatment characteristics of the cohort are summarised in Appendix Table 1. Appendix Table 2 summarises the maximum grade of AE occurring within the first 42 days of lapatinib plus capecitabine therapy, and within the entire follow up period. 
Table 1. Summary of participant characteristics in the EMLIA analysis dataset

\begin{tabular}{|c|c|}
\hline Summary of patient characteristics & Total Number 488 \\
\hline The actual treatment given & $488(100 \%)$ \\
\hline Age (years) & $53(46-61)$ \\
\hline \multicolumn{2}{|l|}{ Race } \\
\hline White & $367(75 \%)$ \\
\hline Asian & $85(17 \%)$ \\
\hline Black or African American & $21(4 \%)$ \\
\hline American Indian or Alaska Native & $7(1 \%)$ \\
\hline Native Hawaiian or Other Pacific Islander & $3(1 \%)$ \\
\hline Other & $5(1 \%)$ \\
\hline \multicolumn{2}{|l|}{ Race } \\
\hline Non-White & $121(25 \%)$ \\
\hline White & $367(75 \%)$ \\
\hline \multicolumn{2}{|l|}{ Race } \\
\hline Non-Asian & $403(83 \%)$ \\
\hline Asian & $85(17 \%)$ \\
\hline \multicolumn{2}{|l|}{ Weight (Kg) } \\
\hline Median (IQR) & $68(59-79)$ \\
\hline Missing & $9(2 \%)$ \\
\hline \multicolumn{2}{|l|}{ ECOG Performance status } \\
\hline 0 & $308(63 \%)$ \\
\hline 1 & $172(35 \%)$ \\
\hline Missing & $8(2 \%)$ \\
\hline Visceral disease site at baseline & $328(67 \%)$ \\
\hline \multicolumn{2}{|l|}{ Months from initial diagnosis } \\
\hline Median (IQR) & $40(18-77)$ \\
\hline Missing & $2(0 \%)$ \\
\hline \multicolumn{2}{|l|}{ Progesterone Receptor Status } \\
\hline Positive & $169(35 \%)$ \\
\hline Negative & $304(62 \%)$ \\
\hline Missing & $15(3 \%)$ \\
\hline \multicolumn{2}{|l|}{ Estrogen Receptor Status } \\
\hline Positive & $244(50 \%)$ \\
\hline Negative & $237(49 \%)$ \\
\hline Missing & $7(1 \%)$ \\
\hline \multicolumn{2}{|c|}{ HER2 Status Fluorescence In-Situ Hybridisation } \\
\hline Positive & $438(90 \%)$ \\
\hline Negative & $6(1 \%)$ \\
\hline Missing & $44(9 \%)$ \\
\hline \multicolumn{2}{|l|}{ HER2 Status Immunohistochemistry } \\
\hline $0+$ & $2(0 \%)$ \\
\hline $1+$ & $2(0 \%)$ \\
\hline $2+$ & $54(11 \%)$ \\
\hline $3+$ & $429(88 \%)$ \\
\hline Missing & $1(0 \%)$ \\
\hline Any prior trastuzumab all settings & $488(100 \%)$ \\
\hline Any prior anthracycline all settings & $297(61 \%)$ \\
\hline Any prior taxane all settings & $486(100 \%)$ \\
\hline
\end{tabular}

There was a significant association between rash occurring within the first 42 days of lapatinib plus capecitabine therapy and improved OS (HR [95\% CI] Grade $1=0.67$ [0.46-0.98], Grade 2+ = 0.71 [0.42-1.19]; $p=0.046)$. There was also a significant association between hand-foot syndrome and improved OS (HR [95\% CI]: Grade $1=0.58$ [0.43-0.80], Grade $2+=0.61$ $[0.43-0.86] ; p=<0.001)$. Nausea and vomiting (particularly Grade 2+) was significantly associated with worsened OS (HR [95\%CI] Grade $1=1.08$ [0.82-1.42], Grade 2+ = 1.52 [1.13-2.03]; $p=0.027)$. No statistically significant associations between rash (HR [95\% CI] Grade $1=0.82$ [0.58-1.16], Grade 2+ $=0.68$ $[0.40-1.17] ; p=0.197)$, hand-foot syndrome (HR $[95 \% \mathrm{CI}]$ Grade $1=0.75[0.56-1.00]$, Grade $2+=1.04$
[0.75-1.44]; $p=0.106)$, or nausea and vomiting (HR [95\%CI] Grade $1=1.11$ [0.85-1.45], Grade 2+ = 1.41 [1.05-1.90]; $p=0.084$ ) occurring with the first 42 days of lapatinib plus capecitabine therapy and PFS was observed (Appendix Table 3). Further, diarrhoea, decreased appetite, gastrointestinal inflammation, and fatigue/ asthenia were not associated with either of OS or PFS outcomes (Appendix Table 3).

Appendix Figure 1 presents Kaplan Meier estimates of OS and PFS by maximum grade of rash, hand foot syndrome and nausea/ vomiting occurring within the first 42 days of lapatinib plus capecitabine treated $\mathrm{ABC}$ patients within EMILIA.

The significant association between rash and hand-foot syndrome with improved OS were confirmed on univariable and adjusted time-dependent Cox proportional hazard regression analysis $(p=$ $<0.001$, Appendix Table 4). The significant association between nausea and vomiting with worsened OS was confirmed on univariable analysis $(p=0.044)$, albeit only a substantial trend towards worsened OS was observed for those experiencing grade $2+$ nausea and vomiting on adjustment $(p=0.134$, Appendix Table 4$)$.

Table 2. Summary of maximum grade of $A E$ within the first 42 days of lapatinib plus capecitabine, and within the entire follow up period

\begin{tabular}{|c|c|c|}
\hline & First 42 days & Entire follow up \\
\hline \multicolumn{3}{|l|}{ Rash* } \\
\hline Grade 0 & $402(82 \%)$ & $342(70 \%)$ \\
\hline Grade 1 & $58(12 \%)$ & $83(17 \%)$ \\
\hline Grade 2+ & $28(6 \%)$ & $63(13 \%)$ \\
\hline \multicolumn{3}{|c|}{ Hand Foot Syndrome } \\
\hline Grade 0 & $336(69 \%)$ & $197(40 \%)$ \\
\hline Grade 1 & $89(18 \%)$ & $66(14 \%)$ \\
\hline Grade 2+ & $63(13 \%)$ & $225(46 \%)$ \\
\hline \multicolumn{3}{|c|}{ Nausea and Vomiting } \\
\hline Grade 0 & $290(59 \%)$ & $218(45 \%)$ \\
\hline Grade 1 & $114(23 \%)$ & $148(30 \%)$ \\
\hline Grade 2+ & $84(17 \%)$ & $122(25 \%)$ \\
\hline \multicolumn{3}{|l|}{ Diarrhoea } \\
\hline Grade 0 & $167(34 \%)$ & $99(20 \%)$ \\
\hline Grade 1 & $148(30 \%)$ & $146(30 \%)$ \\
\hline Grade 2+ & $173(35 \%)$ & $243(50 \%)$ \\
\hline \multicolumn{3}{|c|}{ Decreased Appetite } \\
\hline Grade 0 & $404(83 \%)$ & $371(76 \%)$ \\
\hline Grade 1 & $59(12 \%)$ & $78(16 \%)$ \\
\hline Grade 2+ & $25(5 \%)$ & $39(8 \%)$ \\
\hline \multicolumn{3}{|c|}{ Gastrointestinal Inflammation\# } \\
\hline Grade 0 & $372(76 \%)$ & $336(69 \%)$ \\
\hline Grade 1 & $76(16 \%)$ & $89(18 \%)$ \\
\hline Grade 2+ & $40(8 \%)$ & $63(13 \%)$ \\
\hline \multicolumn{3}{|c|}{ Fatigue and Asthenia } \\
\hline Grade 0 & $359(74 \%)$ & $269(55 \%)$ \\
\hline Grade 1 & $81(17 \%)$ & $112(23 \%)$ \\
\hline Grade 2+ & $48(10 \%)$ & $107(22 \%)$ \\
\hline
\end{tabular}

Data are number of patients (\%). * - combined variable of preferred terms rash, exfoliative rash, rash pruritic, rash macular, rash erythematous, rash pustular, rash maculo-papular, rash papular, rash vesicular, and rash generalized. \# - combined variable of preferred terms mucosal inflammation and stomatitis 

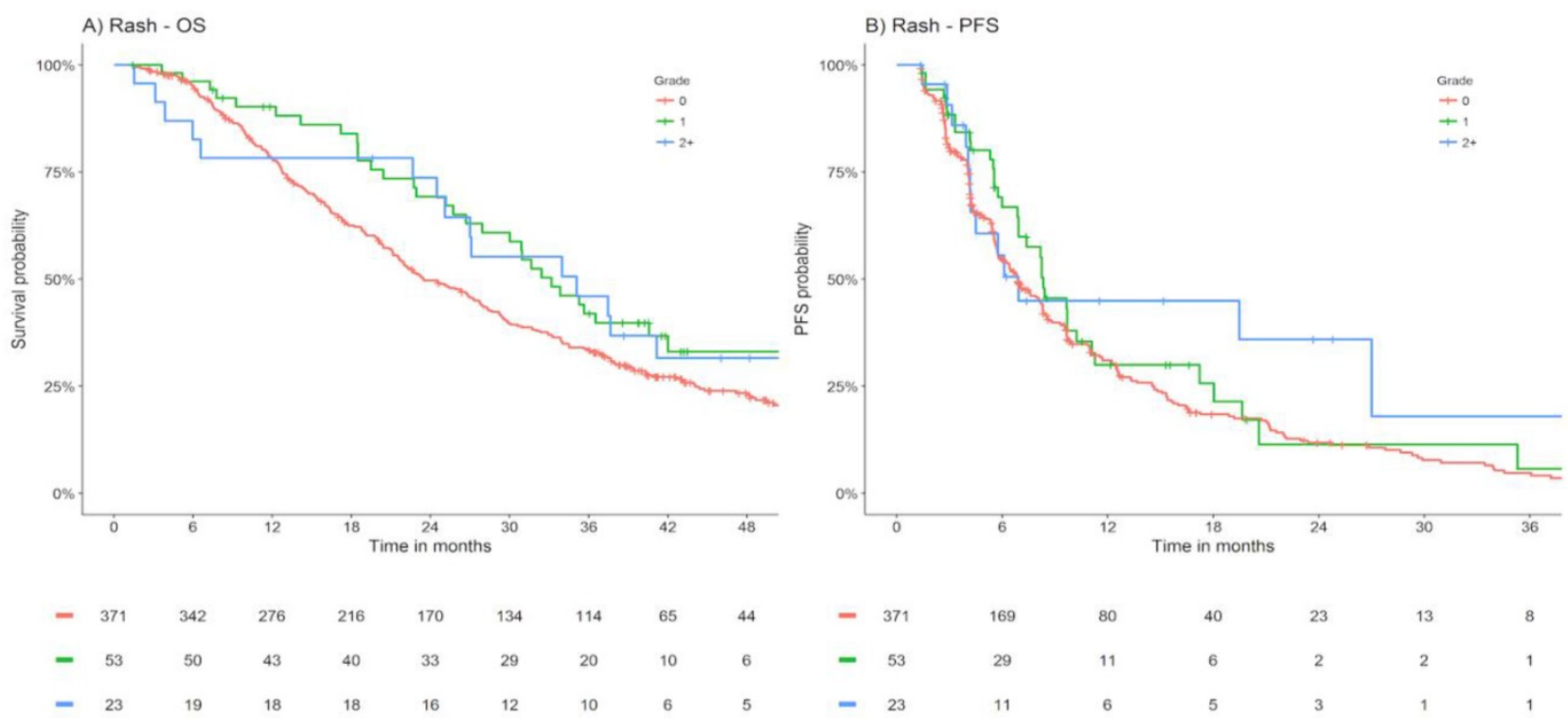

C) Handfoot Syndrome - OS

D) Handfoot Syndrome - PFS
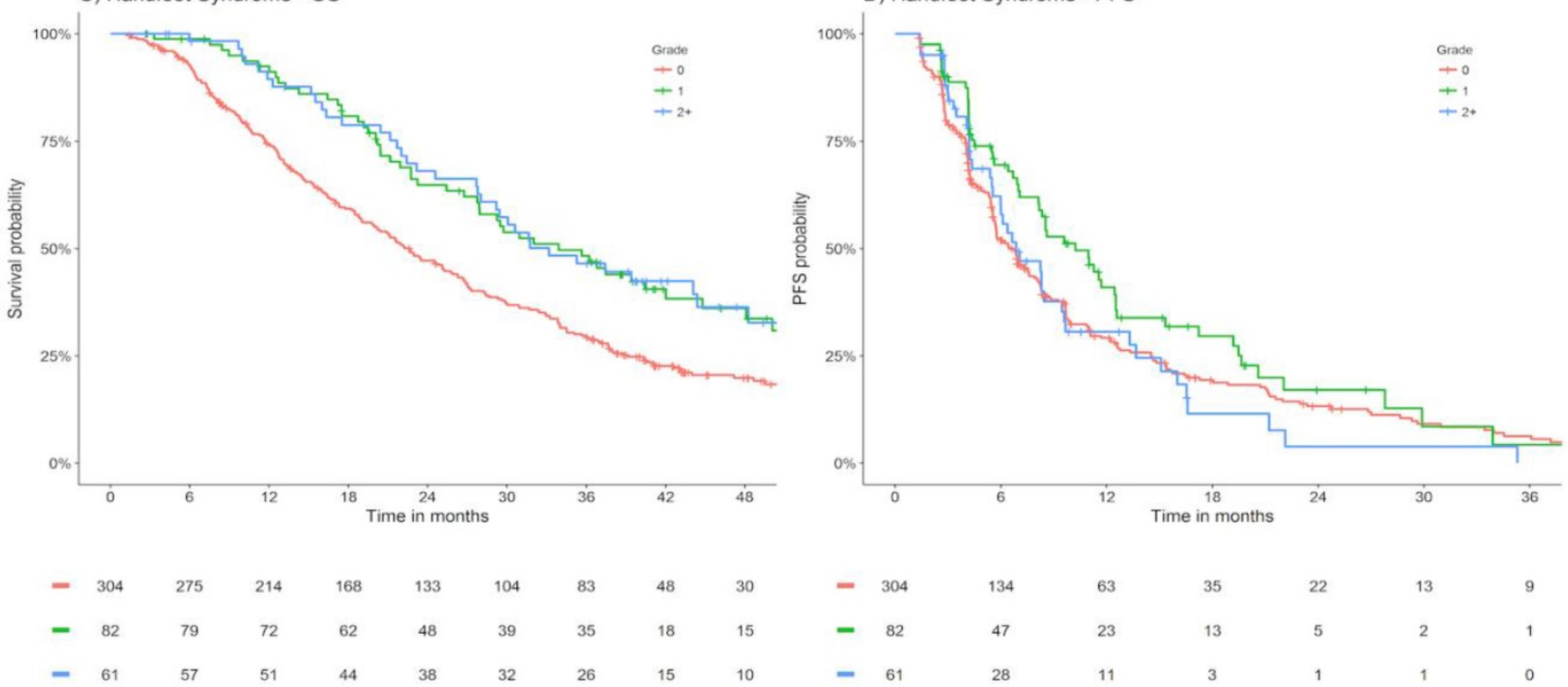

E) Nausea/ Vomitting - OS

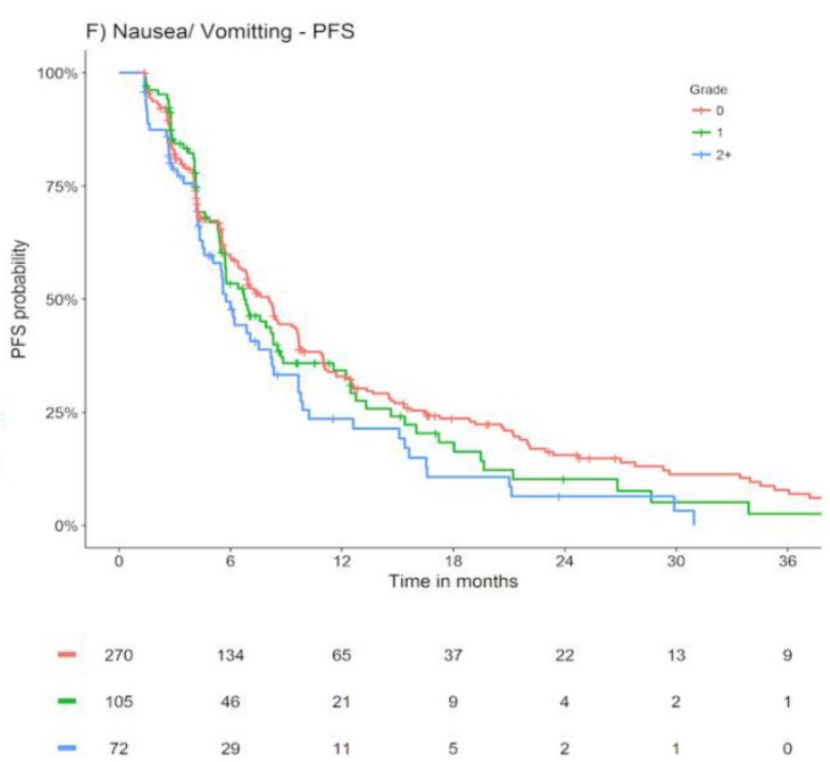

Figure 1. OS and PFS stratified by maximum grade of rash, hand foot syndrome, nausea/ vomiting within the first 42 days of lapatinib plus capecitabine treated $A B C$ patients from EMILIA. Abbreviations: OS - overall survival, PFS - progression free survival. 
Table 3. Summary of association between maximum grade of $A E$, OS and PFS within the first 42 days of lapatinib plus capecitabine therapy

\begin{tabular}{|c|c|c|c|c|c|}
\hline \multirow[b]{2}{*}{ Variable } & \multirow[b]{2}{*}{$\mathbf{N}$} & \multicolumn{2}{|l|}{ OS } & \multicolumn{2}{|l|}{ PFS } \\
\hline & & HR [95\% CI] & $p$ & HR $[95 \% \mathrm{CI}]$ & $p$ \\
\hline Rash & & & 0.046 & & 0.197 \\
\hline Grade 0 & 371 & 1.00 & & 1.00 & \\
\hline Grade 1 & 53 & $0.67[0.46-0.98]$ & & $0.82[0.58-1.16]$ & \\
\hline Grade 2+ & 23 & $0.71[0.42-1.19]$ & & $0.68[0.40-1.17]$ & \\
\hline \multicolumn{2}{|c|}{ Hand Foot Syndrome } & & $<0.001$ & & 0.106 \\
\hline Grade 0 & 304 & 1.00 & & 1.00 & \\
\hline Grade 1 & 82 & $0.58[0.43-0.80]$ & & $0.75[0.56-1.00]$ & \\
\hline Grade 2+ & 61 & $0.61[0.43-0.86]$ & & $1.04[0.75-1.44]$ & \\
\hline \multicolumn{2}{|c|}{ Nausea and Vomiting } & & 0.027 & & 0.084 \\
\hline Grade 0 & 270 & 1.00 & & 1.00 & \\
\hline Grade 1 & 105 & $1.08[0.82-1.42]$ & & $1.11[0.85-1.45]$ & \\
\hline Grade 2+ & 72 & $1.52[1.13-2.03]$ & & $1.41[1.05-1.90]$ & \\
\hline Diarrhoea & & & 0.142 & & 0.539 \\
\hline Grade 0 & 153 & 1.00 & & 1.00 & \\
\hline Grade 1 & 138 & $0.80[0.61-1.05]$ & & $0.87[0.67-1.14]$ & \\
\hline Grade 2+ & 156 & $0.79[0.60-1.02]$ & & $0.89[0.69-1.15]$ & \\
\hline \multicolumn{2}{|c|}{ Decreased Appetite } & & 0.603 & & 0.787 \\
\hline Grade 0 & 370 & 1.00 & & 1.00 & \\
\hline Grade 1 & 57 & $0.98[0.70-1.38]$ & & $1.04[0.74-1.45]$ & \\
\hline Grade 2+ & 20 & $0.75[0.42-1.34]$ & & $1.22[0.70-2.13]$ & \\
\hline \multicolumn{3}{|c|}{ Gastrointestinal Inflammation } & 0.169 & & 0.17 \\
\hline Grade 0 & 340 & 1.00 & & 1.00 & \\
\hline Grade 1 & 71 & $0.74[0.53-1.02]$ & & $0.77[0.56-1.06]$ & \\
\hline Grade 2+ & 36 & $0.94[0.63-1.41]$ & & $0.80[0.53-1.20]$ & \\
\hline \multicolumn{2}{|c|}{ Fatigue and Asthenia } & & 0.105 & & 0.54 \\
\hline Grade 0 & 330 & 1.00 & & 1.00 & \\
\hline Grade 1 & 75 & $0.73[0.53-1.00]$ & & $0.92[0.68-1.23]$ & \\
\hline Grade 2+ & 42 & $1.08[0.75-1.56]$ & & $0.83[0.57-1.20]$ & \\
\hline
\end{tabular}

Abbreviations: CI - confidence interval, HR - hazard ratio, OS - overall survival, PFS - progression free survival, N - Number

Table 4. Summary of the association between grade of rash, hand-foot syndrome and nausea plus vomiting with OS in time-dependent Cox proportional hazard regression analysis

\begin{tabular}{|c|c|c|c|c|}
\hline \multirow[b]{2}{*}{ Variable } & \multicolumn{2}{|c|}{ Univariable analysis } & \multicolumn{2}{|c|}{ Adjusted analysis } \\
\hline & HR [95\% CI] & $\mathrm{p}$ & HR [95\% CI] & $\mathrm{p}$ \\
\hline Rash & & $<0.001$ & & $<0.001$ \\
\hline Grade 0 & 1.00 & & 1.00 & \\
\hline Grade 1 & $0.51[0.37-0.71]$ & & $0.52[0.37-0.72]$ & \\
\hline Grade 2+ & $0.65[0.46-0.92]$ & & $0.62[0.43-0.89]$ & \\
\hline \multicolumn{2}{|c|}{ Hand Foot Syndrome } & $<0.001$ & & $<0.001$ \\
\hline Grade 0 & 1.00 & & 1.00 & \\
\hline Grade 1 & $0.63[0.45-0.88]$ & & $0.57[0.40-0.80]$ & \\
\hline Grade 2+ & $0.56[0.45-0.71]$ & & $0.53[0.42-0.69]$ & \\
\hline \multicolumn{2}{|c|}{ Nausea and Vomiting } & 0.044 & & 0.134 \\
\hline Grade 0 & 1.00 & & 1.00 & \\
\hline Grade 1 & $1.00[0.77-1.29]$ & & $0.95[0.73-1.24]$ & \\
\hline Grade 2+ & $1.37[1.05-1.78]$ & & $1.26[0.96-1.66]$ & \\
\hline
\end{tabular}

\section{Discussion}

The present study identified $\mathrm{ABC}$ patients who experienced rash and hand-foot syndrome within the first 42 days of lapatinib plus capecitabine therapy had improved OS. Conversely, ABC patients who experienced nausea and vomiting within the first 42 days of lapatinib plus capecitabine therapy had worse OS.

Lapatinib-induced rash is an effect of the drugs actions on the ErbB-1 receptor [13]. Prior studies have indicated the development of a rash with ErbB-1 inhibitors is associated with better survival outcomes in non-small cell lung and pancreatic cancer patients [14]. Further, the identified association herein between lapatinib plus capecitabine therapy induced rash and improved OS is similar to results observed in early breast cancer patients treated with lapatinib; the Neoadjuvant Lapatinib and/or Trastuzumab Treatment Optimisation (NeoALTTO) trial and Adjuvant Lapatinib and/or Trastuzumab Treatment Optimisation (ALTTO) trial demonstrated that early rash was associated with higher rates of pathological complete response, and improved OS respectively $[10,15]$.

The pharmacological mechanism of capecitabine-associated hand-foot syndrome is still unclear, however preliminary data suggests that the capecitabine-metabolizing enzyme, thymidine phosphorylase, is frequently highly expressed in the palms, leading to elevated local production of 5-fluorouracil, resulting in hand-foot syndrome [16]. Similarly, studies have shown that high tumor expression of thymidine phosphorylase is associated with improved survival outcomes [17, 18]. Given this information, it is not surprising that prior studies have indicated the development of early hand-foot syndrome (landmark analysis at 3 months) [19] and hand foot syndrome at any time [20] are associated with better survival outcomes in $\mathrm{ABC}$ receiving capecitabine, and our study demonstrated hand foot syndrome to be associated with improved OS in ABC receiving lapatinib plus capecitabine.

Age, performance status, prior and concomitant therapies and history of anticipatory nausea and vomiting are known predictors of chemotherapy induced nausea and vomiting [21]. The biological rationale by which lapatinib plus capecitabineinduced nausea and vomiting mediates worse OS was not identified within this study but may be a reflection that nausea and vomiting is not related to on-target effects of lapatinib or capecitabine. While the mechanism was not identified, it is not surprising as chemotherapy-induced nausea and vomiting can impact the quality-of-life of cancer patients, and patient-reported outcomes are associated with survival outcomes [22]. Given this prior evidence and the observation herein that $\mathrm{ABC}$ patients who experienced nausea and vomiting within the first 42 days of lapatinib plus capecitabine therapy have worse OS, at risk individuals of lapatinib plus capecitabine induced nausea and vomiting should be closely monitored to minimise its potential occurrence - potentially via the addition of antiemetic prophylaxis.

The strengths of this study are the large sample size and the quality of data collected within the 
EMILIA trial. Further, the landmark analysis at 42 days provides the clinician with useful information early in treatment, thus potentially facilitating timely management to optimize patient outcomes. The results have also been confirmed in a sensitivity time-dependent Cox proportional hazards analysis. A potential study limitation is that clinical trials do not include all patients who may be treated in routine clinical care (i.e. strict inclusion criteria), and the EMILIA trial may not represent the most contemporary line of lapatinib plus capecitabine use in real-world practice. Thus, future studies will have a role in investigating the identified associations within a real-world cohort of $A B C$ patients treated with lapatinib plus capecitabine. It is of interest to quantify the impact of the clinical trial setting as compared to routine clinical practice on the identified associations. Further, future studies should investigate the associations between lapatinib or capecitabine induced $\mathrm{AE}$ and outcomes when used in different settings, for example, early rash developed secondary to lapatinib in the adjuvant/neoadjuvant setting is approximately $50 \%$ which is significantly higher than herein $[10,15]$.

While lapatinib plus capecitabine-induced rash and hand foot syndrome was significantly associated with improved OS, and nausea and vomiting with worse OS; the associations of these AE with PFS were not statistically significant. The reason for this discrepancy is unclear, however PFS is an imperfect surrogate marker, which may be affected by variability in timing of assessments, investigators and measurement biases [23, 24]. Further, assessed association with OS may be confounded by drug cessation, crossover or subsequent therapies [23, 24]. An appreciation of these points indicates that the identified associations may not be isolated to lapatinib plus capecitabine. Rather they may represent individuals with greater sensitivity to anti-cancer medicines - which compounds to significant OS differences (appreciating that there were consistent trends, but not statistically significant associations, identified with PFS for lapatinib plus capecitabine induced-rash, hand-foot syndrome and nausea and vomiting).

In conclusion, $\mathrm{ABC}$ patients who experienced rash and hand-foot syndrome in the first 42 days of lapatinib plus capecitabine therapy had improved OS within EMILIA. This finding suggests that early rash or hand-foot syndrome could function as surrogate markers of therapeutic efficacy, and thus dose-escalation to grade 1 or 2 rash or hand-foot syndrome may translate into improved clinical outcomes in $\mathrm{ABC}$ patients treated with lapatinib plus capecitabine. Conversely, ABC patients who experienced nausea and vomiting within the first 42 days of lapatinib plus capecitabine therapy had worse OS, indicating that close monitoring of individuals at a high risk of lapatinib plus capecitabine induced nausea and vomiting is advisable.

\section{Abbreviations}

AE: adverse events; PFS: progression-free survival; OS: overall survival; HER2: human epidermal growth factor receptor 2; ABC: advanced breast cancer; HR: Hazard Ratio; CI: Confidence Interval; EGFR: epidermal growth factor receptor; mRECIST: modified Response Evaluation Criteria in Solid Tumours version; CTCAE: Common Terminology Criteria for Adverse Events.

\section{Acknowledgements}

Fang L.I. Ang would like to acknowledge the advice and contributions of Hoi Yee Yuen.

\section{Ethics Committee Approval and Patient Consent}

This study analysed individual-participant data collected within the randomized trial EMILIA (NCT00 829166). Secondary data analysis was approved by the Southern Adelaide Clinical Human Research Ethics Committee Approval number OFR \#488.15.

\section{Data Availability Statement}

Data in this study were accessed according to Roche's policy and process for clinical study data sharing. All data are available via clinicalstudydata request.com.

\section{Funding Statement}

Research undertaken with the financial support of Cancer Council South Australia's Beat Cancer Project on behalf of its donors and the State Government through the Department of Health (Grant ID: 1159924 and 1127220). R.A.M. and A.R. receive salary support from the Cancer Council's Beat Cancer Project with the support from their donors and the South Australian Department of Health. A.M.H. is a researcher funded by a Postdoctoral Fellowship from the National Breast Cancer Foundation, Australia (PF-17-007).

\section{Competing Interests}

M.J.S., R.A.M. and A.R. report grants from Pfizer, outside the scope of the submitted work. The authors have no other conflicts of interest to disclose.

\section{References}

1. Giordano SH, Temin S, Chandarlapaty S, Crews JR, Esteva FJ, Kirshner JJ, et al. Systemic Therapy for Patients With Advanced Human Epidermal Growth Factor Receptor 2-Positive Breast Cancer: ASCO Clinical Practice Guideline Update. J Clin Oncol. 2018; 36: 2736-40. 
2. Medina PJ, Goodin S. Lapatinib: a dual inhibitor of human epidermal growth factor receptor tyrosine kinases. Clin Ther. 2008; 30: 1426-47.

3. Walko CM, Lindley C. Capecitabine: a review. Clin Ther. 2005; 27: 23-44.

4. Cameron D, Casey M, Oliva C, Newstat B, Imwalle B, Geyer CE. Lapatinib plus capecitabine in women with HER-2-positive advanced breast cancer: final survival analysis of a phase III randomized trial. Oncologist. 2010; 15: 924-34.

5. Petrelli F, Ghidini M, Lonati V, Tomasello G, Borgonovo K, Ghilardi M, et al. The efficacy of lapatinib and capecitabine in HER-2 positive breast cancer with brain metastases: A systematic review and pooled analysis. Eur J Cancer. 2017; 84: $141-8$

6. Bachelot T, Romieu G, Campone M, Dieras V, Cropet C, Dalenc F, et al. Lapatinib plus capecitabine in patients with previously untreated brain metastases from HER2-positive metastatic breast cancer (LANDSCAPE): a single-group phase 2 study. Lancet Oncol. 2013; 14: 64-71.

7. Choi HD, Chang MJ. Cardiac toxicities of lapatinib in patients with breast cancer and other HER2-positive cancers: a meta-analysis. Breast Cancer Res Treat. 2017; 166: 927-36.

8. Dieras V, Miles D, Verma S, Pegram M, Welslau M, Baselga J, et al. Trastuzumab emtansine versus capecitabine plus lapatinib in patients with previously treated HER2-positive advanced breast cancer (EMILIA): a descriptive analysis of final overall survival results from a randomised, open-label, phase 3 trial. Lancet Oncol. 2017; 18: 732-42.

9. Araki K, Fukada I, Horii R, Takahashi S, Akiyama F, Iwase T, et al. Lapatinib-associated mucocutaneous toxicities are clinical predictors of improved progression-free survival in patients with human epidermal growth factor receptor (HER2)-positive advanced breast cancer. Breast Cancer Res Treat. 2014; 148: 197-209.

10. Sonnenblick A, de Azambuja E, Agbor-Tarh D, Bradbury I, Campbell C, Huang Y, et al. Lapatinib-Related Rash and Breast Cancer Outcome in the ALTTO Phase III Randomized Trial. J Natl Cancer Inst. 2016; 108: djw037.

11. Azuma Y, Hata K, Sai K, Udagawa R, Hirakawa A, Tohkin M, et al. Significant association between hand-foot syndrome and efficacy of capecitabine in patients with metastatic breast cancer. Biol Pharm Bull. 2012; 35: 717-24.

12. Verma S, Miles D, Gianni L, Krop IE, Welslau M, Baselga J, et al. Trastuzumab emtansine for HER2-positive advanced breast cancer. N Engl J Med. 2012; 367: 1783-91.

13. Moy B, Goss PE. Lapatinib-associated toxicity and practical management recommendations. Oncologist. 2007; 12: 756-65.

14. Wacker B, Nagrani T, Weinberg J, Witt K, Clark G, Cagnoni PJ. Correlation between Development of Rash and Efficacy in Patients Treated with the Epidermal Growth Factor Receptor Tyrosine Kinase Inhibitor Erlotinib in Two Large Phase III Studies. Clin Cancer Res. 2007; 13: 3913-21.

15. Azim HA Jr, Agbor-Tarh D, Bradbury I, et al. Pattern of rash, diarrhea, and hepatic toxicities secondary to lapatinib and their association with age and response to neoadjuvant therapy: analysis from the NeoALTTO trial. J Clin Oncol. 2013; 31(36): 4504-11.

16. Milano G, Etienne-Grimaldi M-C, Mari M, Lassalle S, Formento J-L, Francoual $\mathrm{M}$, et al. Candidate mechanisms for capecitabine-related hand-foot syndrome. Br J Clin Pharmacol. 2008; 66: 88-95.

17. Puglisi F, Cardellino GG, Crivellari D, Di Loreto C, Magri MD, Minisini AM, et al. Thymidine phosphorylase expression is associated with time to progression in patients receiving low-dose, docetaxel-modulated capecitabine for metastatic breast cancer. Ann Oncol. 2008; 19: 1541-6.

18. Fox SB, Engels K, Comley M, Whitehouse RM, Turley H, Gatter KC, et al. Relationship of elevated tumour thymidine phosphorylase in node-positive breast carcinomas to the effects of adjuvant CMF. Ann Oncol. 1997; 8: 271-5

19. Zielinski C, Lang I, Beslija S, Kahan Z, Inbar MJ, Stemmer SM, et al. Predictive role of hand-foot syndrome in patients receiving first-line capecitabine plus bevacizumab for HER2-negative metastatic breast cancer. Br J Cancer. 2016; 114: $163-70$.

20. Kaufmann M, Maass N, Costa SD, Schneeweiss A, Loibl S, Sutterlin MW, et al. First-line therapy with moderate dose capecitabine in metastatic breast cancer is safe and active: results of the MONICA trial. Eur J Cancer. 2010; 46: 3184-91.

21. Dranitsaris G, Molassiotis A, Clemons M, Roeland E, Schwartzberg L, Dielenseger $\mathrm{P}$, et al. The development of a prediction tool to identify cancer patients at high risk for chemotherapy-induced nausea and vomiting. Annals of oncology : official journal of the European Society for Medical Oncology. 2017; 28: 1260-7.

22. Osoba D. Health-related quality of life and cancer clinical trials. Ther Adv Med Oncol. 2011; 3: 57-71.

23. Hotte SJ, Bjarnason GA, Heng DYC, Jewett MAS, Kapoor A, Kollmannsberger C, et al. Progression-free survival as a clinical trial endpoint in advanced renal cell carcinoma. Curr Oncol. 2011; 18 Suppl 2: S11-S9.

24. Pazdur R. Endpoints for assessing drug activity in clinical trials. Oncologist. 2008; 13 Suppl 2: 19-21. 